\title{
Are Workers Rewarded for Inconsistent Performance?
}

\section{ANIL ÖZDEMIR (D, HELMUT DIETL, GIAMBATTISTA ROSSI and ROB SIMMONS}

\begin{abstract}
This paper examines whether workers are rewarded for inconsistent performance by salary premia. Some earlier research suggests that performance inconsistency leads to salary premia, while other research finds premia for consistent performance. Using detailed salary and performance data for top-level footballers in Italy's Serie A, we find that inconsistency is penalized for some important dimensions of basic performance measures associated with key skills of players, specifically clearances, aerial duels won, and shots on target.
\end{abstract}

\section{Introduction}

Following Lazear (1998), a body of personnel economics literature has considered whether workers who demonstrate greater performance inconsistency than comparable workers of similar average productivity are rewarded more highly. Lazear conjectured that there would be an "upside potential to risky workers" such that inconsistent performers would be more highly rewarded due to their capability of providing extraordinarily high productivity, albeit on a few occasions. Firms would consider this unusually high performance to be an option value and would pay workers more to reflect this.

In some cases, principals prefer consistent to volatile performance by their agents (Bodvarsson and Brastow 1998; Deutscher et al. 2017; Dickinson and Oaxaca 2014). In other cases, principals prefer inconsistent agents (Bollinger and Hotchkiss 2003; Deutscher and Büschemann 2016). Although existing literature finds evidence on both sides, the question under which conditions inconsistency is penalized or rewarded remains unanswered.

\footnotetext{
JEL codes: J31, M52, Z20.

${ }^{\dagger}$ The authors' affiliations are, respectively, Department of Business Administration, University of Zurich, Plattenstrasse 14, CH-8032 Zurich, Switzerland. E-mail: anil.oezdemir@business.uzh.ch. Department of Business Administration, University of Zurich, Plattenstrasse 14, CH-8032 Zurich, Switzerland. E-mail: helmut.dietl@business.uzh.ch. Department of Management, Birkbeck, University of London, Malet Street, Bloomsbury, London WC1E 7HX, UK. E-mail: g.rossi@bbk.ac.uk. Department of Economics, Lancaster University, Management School, Lancaster, LA1 4YX, UK. E-mail: r.simmons@lancaster.ac.uk.

Industrial Relations, DOI: 10.1111/irel.12292. (C) 2021 The Authors. Industrial Relations published by Wiley Periodicals LLC on behalf of Regents of the University of California (RUC). Published by Wiley Periodicals, Inc., 350 Main Street, Malden, MA 02148, USA, and 9600 Garsington Road, Oxford, OX4 2DQ, UK. This is an open access article under the terms of the Creative Commons Attribution-NonCommercial License, which permits use, distribution and reproduction in any medium, provided the original work is properly cited and is not used for commercial purposes.
} 


\section{2 / ÖZdemir, DietL, Rossi and Simmons}

Empirical testing for upside potential of risky workers is very difficult in most industries as individual workers' mean and variance of productivity cannot be cleanly derived (Ernst and Vitt 2000; Garen 1988). Self-reported survey data are unhelpful in this context, and results from firm-specific data may not easily generalize (Barrett and O'Connell 2001; Chapman and Southwick 1991), because cross-firm comparisons are not possible.

Instead, sports data offer good opportunities to study the relationship between worker salary and variations in productivity since we can extract performance data at the individual worker (player) level for many different competing firms (clubs) over time (seasons) into a large data set. Kahn (2000) emphasizes that the sports industry presents a valuable laboratory setting to analyze labor markets.

We exploit detailed football performance data from the top division of one of the top five European football leagues, the Italian Serie A. We define performance inconsistency as performance variation and are particularly interested in the effects of performance variation on salary. Some players might be rewarded for performance consistency, whereas others are rewarded for performance variation.

In contrast to Deutscher and Büschemann (2016), who use the same single performance proxy measure (journalist ratings for player performance) for all players regardless of field position in the team and proxies for salaries (player valuations by experts), we use actual performance and salary data, which are clearly superior to market values and other proxies. ${ }^{1}$ Moreover, managers, journalists, and sports fans significantly overrate observed outcomes when they evaluate performance, that is, they demonstrate outcome bias (Gauriot and Page 2019).

Going beyond previous research, we show that salary premia in our setting are not offered for inconsistency. Using numerous on-field performance metrics, we show that inconsistency is penalized for three important dimensions of performance, specifically clearances, aerials won, and shots on target, but has no significant effect on other aspects of performance.

The paper is organized as follows. Section 'Background' provides the theoretical background. Section 'Data and Methods' presents the data and empirical model. In Section 'Regression Results', we analyze empirical results, and we conclude the paper in Section 'Discussion and Conclusion'.

\footnotetext{
${ }^{1}$ Using market values as proxies for salary data (e.g., via Transfermarkt.de or Kicker ratings) raises several issues: (i) the algorithm to calculate market values is non-transparent, (ii) the algorithm does not update frequently, and (iii) crowd estimates cannot be verified or replicated (Müller et al. 2017). Market values conflate transfer fees with salary payments. Thrane (2019) shows the limitations of market values as biased predictors of actual salary in Norwegian football.
} 


\section{Background}

A widely used regression model to explain earnings as a function of schooling and experience is that of Mincer (1974), which has been replicated in many subsequent studies (Ashenfelter and Krueger 1994; Bils and Klenow 2000; Card and Krueger 1992). More-educated workers earn higher salaries; additional years of work experience and age have a positive albeit diminishing effect on salaries (i.e., upward sloping and concave functional form). In sports, researchers have focused largely on Mincer's wage equation to model salary outcomes, where age, experience, position, national team selection, team effects, country of origin, and performance have been examined for potential effects on salaries. Bryson et al. (2013) found that age, height, goals per game, international appearances, and two-footedness increase salaries in football. In general, offensive players earn more (Lucifora and Simmons 2003). Extraordinarily talented football players, "superstars," earn up to 34\% more (Lucifora and Simmons 2003). Evidence for superstar effects is offered by Carrieri et al. (2018), who used Google citations as a measure of player popularity. Moreover, migrant players earn more than domestic ones, which is partly explained by the superstar effects (Bryson et al. 2014).

Rosen's (1981) seminal paper formally analyzed the economics of superstars. Rosen showed that marginal differences in talent can lead to huge differences in earnings. When talent is highly valued by consumers, the most talented individuals earn disproportionately high incomes due to economies of scale in audience consumption of the performer's talent. In modern European football, audience consumption refers to global broadcast coverage of matches featuring superstar players. When superstars are playing, even regular league games are broadcast live across all major continents.

Adler (1985) showed that equally talented individuals might have huge differences in earnings because consumers are more familiar with one compared to the other. The implication is that an individual's celebrity status associated with accumulated reputation, rather than that individual's talent, leads to higher earnings. Rosen's and Adler's explanations of superstar effects are complementary, not mutually exclusive: To qualify as a superstar, a player needs strong performance, high popularity, and the ability to reach a large audience. Players such as Messi and Ronaldo have all three attributes.

Superstar effects are most likely to occur in arts, entertainment, and sports, but they are also observed in other fields. Researchers have focused on the earnings of CEOs (Malmendier and Tate 2009), Wall Street analysts (Groysberg et al. 2008), scientists (Narin and Breitzman 1995), and actors (Ravid 1999) and athletes (Carrieri et al. 2018; Lucifora and Simmons 2003). Using Italian salary data and several different regression methods, including 


\section{4 / Özdemir, Dietl, Rossi And Simmons}

unconditional quantile regressions, Carrieri et al. (2018) found that football players' popularity is the most important determinant of salary in the top decile of the salary distribution. Popularity outweighed performance and bargaining power, thereby supporting Adler's (1985) theory.

Relevant to this discussion is Lazear's (1998) theory of upside potential of risky workers. The principle essentially reduces to the proposition that for a given average worker productivity, the equilibrium wage for a risky worker, that is, one offering inconsistent productivity, will be greater than the equilibrium wage for a safe worker, that is, one offering consistent productivity but with lower maximal values from the worker's productivity distribution. This is the "option value" argument according to which the firm benefits from hiring a worker who occasionally delivers spectacularly high levels of performance.

Some researchers have turned to sports data to find empirical evidence for Lazear's (1998) theory. Bodvarsson and Brastow (1998) analyzed data from the National Basketball Association (NBA). Contrary to Lazear's principle, they found that managers preferred consistent over volatile performance. The authors of the paper suggested that inconsistent NBA players earn less because the players need to be monitored, which is costly.

Bollinger and Hotchkiss (2003) pointed out that there are three key conditions for Lazear's principle of upside potential of risky workers to hold. First, the employer must have some competitive advantage over rival firms in terms of the employment relationship with the worker. One source of competitive advantage is restricted mobility of the worker; another is a firm's knowledge of the worker's ability, which is unavailable to competing firms. Second, there should be a probationary period during which the firm learns the distribution of worker productivity, especially the minimum and maximum productivity values that the worker can deliver. Third, there should be at least some firmspecific component of worker productivity in order that firm-specific human capital is a relevant determinant of the employment contract.

All three conditions would appear to hold in the case of Major League Baseball (MLB) studied by Bollinger and Hotchkiss (2003). There is a long period of service (six years) required before a baseball player achieves free agency status; during this period, the player is restricted in options to move between teams. Rookies and other young players, most often drafted by teams, tend to be sent initially to affiliated minor league teams to hone their skills and gradually reveal their productive potential. Each team has particular coaching and playing strategies. Given that the direct application of the conditions for risky performance benefits seems to hold in baseball, it is not surprising that Bollinger and Hotchkiss's empirical findings support Lazear's principle of upside potential of risky workers. Greater dispersion in baseball hitting skills 
is associated with higher player salary. However, this result held only for younger players on rookie contracts, not for veteran free agents.

An opposing theoretical perspective was offered by Deutscher et al. (2017) in a study of the NBA. The authors' theory proposes that a player's expected output increases with ability but at a decreasing rate: a diminishing returns hypothesis. The rationale for diminishing returns is that a single player cannot win a basketball game on his own but requires teammate co-operation to help deliver team wins. Players of greater ability produce more output (points in basketball games) but are constrained by teammates and, of course, by opponents.

Deutscher et al. (2017) showed that performance inconsistency reduces total expected output of the team. The downside of inconsistency does more harm to the team's expected output than the upside does good. The upshot is that if players $X$ and $Y$ have equal average productivity, but $Y$ is more consistent (less risky), $Y$ should receive higher salary.

In their empirical analysis, Deutscher et al. (2017) distinguished between scoring and non-scoring measures of performance. In basketball, scoring is straightforwardly points achieved via shots and free throws. Non-scoring refers to defensive measures such as blocks, steals, and rebounds, and abilities, which are also important for winning. The authors predicted that greater consistency in both scoring and non-scoring measures would be associated with higher pay. Conversely, these predictions are then in direct opposition to those of Bollinger and Hotchkiss (2003).

The theory set out in Deutscher et al. (2017) need not be confined to basketball. It can potentially be applied to any fluid team sport where players have considerable interaction in team production. We argue that the prediction of negative effects of performance inconsistency on player salary can also apply to professional football. Although there is some specialization of roles in football, where forwards are expected to score goals and defenders are expected to prevent goals from being conceded, this is still a fluid team game where all players are expected to perform all basic tasks. These include (a) passing the ball to teammates to retain possession and preferably create scoring opportunities, (b) making shots on target with the aim of scoring goals, and (c) performing defensive tasks to prevent opponents from scoring. Defensive tasks include (a) intercepting opponents' passes, (b) blocking opponents' shots, (c) tackling, and (d) clearances from opponents' attacking situations. Winning aerial duels is also expected of all players, though whether this is considered offensive or defensive depends on field position.

Moreover, the conditions for upside potential of risky workers set out by Lazear (1998) do not appear to hold for a European football league, at least in comparison to MLB. All football players are essentially free agents with 


\section{6 / ÖZdemir, DietL, Rossi And Simmons}

hardly any restrictions on their movement. One obstacle to movement is that a player signs a long-term contract and to be able to move, the employer may demand a compensation (transfer) fee from the hiring club for loss of the player's services, but this can be overcome by negotiation between parties. Specific human capital is surely less relevant than general human capital for player pay in football. Although some young and inexperienced players are sent on loan to other teams to gain experience, performance of players can still be observed in-house. However, we must recognize that Deutscher and Büschemann (2016) studied the relationship between pay and performance consistency in German Bundesliga and found a positive relationship between inconsistency and player remuneration, in line with Bollinger and Hotchkiss (2003) and in support of Lazear's principle of upside potential of risky workers. Thus, it is fair to conclude that the sign of the relationship between performance inconsistency and pay remains an empirical question to be resolved.

Given the opposing theories on the relationship between performance consistency and player pay set out by Bollinger and Hotchkiss (2003) and Deutscher et al. (2017) and conflicting empirical evidence, we propose to examine the relationship between player pay and player performance variation using a rich and detailed data set from Italy's Serie A. We offer the following four possible outcomes of performance on pay. Note that "performance" for any given metric refers to its both mean and standard deviation, where mean performance is the average score over a season and standard deviation of performance is the dispersion of scores across all games played in a given season.

1. The mean of a performance measure has positive impact on pay; the standard deviation also has a positive effect. This result would fit Lazear's principle of upside potential of risky workers with option value.

2. The mean of a performance measure has positive impact on pay; the standard deviation has a negative effect. This result would be consistent with the theory of Deutscher et al. (2017).

3. The mean of a performance measure has positive impact on salary; the standard deviation has zero effect. Here, the team has no view on desirability or otherwise of performance consistency. Either performance variations are treated as noise, or any systematic component is fully incorporated (through full information) with mean performance determining pay (Lazear 1998).

4. The mean of a performance measure has no impact on salary; the standard deviation of the measure has a positive or negative impact on pay. Here, the team does not value the performance measure per se. There is an average level that team members are 
expected to fulfill, but this is not rewarded. Instead, the team rewards or penalizes players for inconsistent performance around the expected mean. This possibility has not been explored in the literature thus far. Nevertheless, we consider it relevant in the context of football, which is a low-scoring game where mistakes matter, especially when these emanate from defensive tasks. We predict that inconsistency in defensive tasks will be penalized in salary, but larger average numbers for some defensive metrics need not result in greater pay.

\section{Data and Methods}

In European football leagues, teams compete against each other with 11 players on each side; the team that scores more goals wins, hence, the objective team production function is to produce more goals than a given opponent in a particular match. Players have different tasks: goalkeepers guard the goal and are allowed to use their hands; defenders try to keep the ball as far away from their goals as possible; midfielders connect defense and attack (some have coordinating tasks, others have creative ones); strikers need to be creative to outplay the opponent's defenders in order to score goals. To oversimplify: attackers proactively seek to outplay defenders, whereas defenders anticipate and react to opponents' moves and try to minimize any mistakes.

To study the heterogeneous relationship between inconsistent worker performance and earnings, we require a detailed data set with information on numerous performance metrics and pay. For this, we use player performance data from eight seasons (2009/10 to 2016/17) of the Italian Serie A. Our choice of Italy's Serie A is motivated by availability of both player salary and player performance data. Italy is the only European country for which reliable and consistent football player salary data are published in a comprehensive manner over a long period (Bryson et al. 2014; Carrieri et al. 2018).

Contracts in European football are rolling, that is, they can be renewed at any time during or after a season depending on the performance of the player or the team (Buraimo et al. 2015). Usually, the majority of players do not play to the end of their contracts: They either transfer to another club or renew their contract with the same club. This is different from MLB because the labor market there is more regulated through player unions, collective bargaining agreements, draft systems, and the like. For instance, a player needs to serve six years in the Major League to become a free agent unless he is released from his club earlier. 


\section{8 / ÖZdemir, Dietl, Rossi And Simmons}

For the evaluation of salary returns to skills, we considered but rejected four alternative approaches. First, we ruled out journalist rankings along the lines of Kicker grades published for German Bundesliga and used by Deutscher and Büschemann (2016). These are necessarily subjective and therefore may be biased for (or against) particular players and particular performance attributes, such as goals and assists.

Second, www.whoscored.com publishes a composite rating for a given player in a given match. In Italy, another composite indicator, IVG, is provided by Panini Digital and used by clubs, media commentators, and academic researchers (Fumarco and Rossi 2018). We consider these composite indicators to be flawed for the purpose of salary evaluation. For our sample, on a scale of 0 to 10 , the Who Scored rating varies only between 5.8 and 8.2, which appears to be an unduly cramped range of values. IVG has a mean of 17 but also has narrow dispersion with standard deviation of 1.5. It is hard to discern what a unit increase in this measure really means. Both composite indicators are determined econometrically by the skill measures that we use below. However, the weights on the contributions of these measures to the index may not reflect their contributions to salary, which is what we want to assess.

A third approach to evaluation of player skills would be to aggregate these measures of skill into factor loadings using either principal component analysis or factor analysis. These methods are widely used in various social science disciplines (Cattell 1978; Mueller and Kim 1978). We attempted a factor analysis using our data. Although we could construct factors that, loosely defined, would conceivably represent "defensive" and "attacking" skills, we also found some anomalies from this approach. Specifically, in the defensive factor, dribbles and assists made negative contributions to factor loadings. Performing more dribbles and providing more assists appear to lead to worse defensive performance. We do not see a credible explanation for these results. Given such anomalies, we prefer to move away from factor analysis, even though this does result in smaller set of performance indicators.

Recently, Kempa (2021) has evaluated salary returns to player tasks in the German Bundesliga, where tasks were associated with on-field player roles, as assigned by www.transfermarkt.de. This website offers nine positional categories, so the classification is finer than just the typical defender, midfielder, and forward typology that we adopt. But each role requires a combination of basic core skills: passing, heading, and clearances in particular. Moreover, the roles taken on by players will depend on tactical team formations assigned by the coach and these can vary within and across games. Because we have detailed performance metrics of key skills, we prefer to use these directly in our estimations. A problem with using direct and detailed performance metrics, however, is the sheer number of available measures. We prefer a degree of 
parsimony in our modeling while retaining our focus on salary returns to levels and (in)consistency of key skills of players.

In total, we count 84,499 player-match observations. This number reduces to 78,302 when goalkeepers are excluded from our analysis, because assessing individual goalkeeper performance is very difficult. The salary data come from the most popular sports newspaper, La Gazzetta dello Sport; this information has been published every September since 2008. The salary data represent gross basic pay and exclude performance-related bonuses, such as payments for team wins and for meeting specified team targets (e.g., league placings and qualification for the supranational UEFA Champions' League).

In order to estimate salary models, we collapse our match-level performance statistics into season-level aggregates. The 14 metrics available from www. whoscored.com from which we can extract seasonal means and standard deviations are as follows: goals, assists, shots, shots on target, passes, key passes, aerial duels won, dribbles, tackles, clearances, blocked shots, accurate crosses, through balls, and interceptions. Each measure was scaled by minutes played in a season; otherwise, a high value of performance could simply be a consequence of more time spent by the player on the pitch.

From these 14 performance measures, we first excluded goals and assists from preliminary estimation. This may appear a curious choice, as several studies have used goals and assists as primary-sometimes only-performance measures (Carrieri et al. 2018; Lucifora and Simmons 2003). We prefer shots on target rather than goals, and key passes rather than assists. A goal is an outcome of (a) the attacking player's skill, (b) the (in)capability of opponent's defenders, including the opposition goalkeeper, and (c) luck, as highlighted by Gauriot and Page (2019). In itself, a goal is not a key skill but instead is an outcome of a shot on target which we do consider a key skill. We conjecture that a player has a degree of control over a shot on target. A player with greater shooting ability will have more shots on target per minute than a player with lesser shooting ability (Berri et al. 2016).

Similarly, an assist is the final pass leading to a goal. Again, assists depend partly on luck and defensive (in)capability. In contrast, a "key pass" is defined as a pass leading to a shot at goal, excluding goals scored. Like shots on target, key passes are under a greater degree of player control than are assists.

\section{Econometric Strategy}

Based on the Mincer wage equation and on the literature on salary determination in team sports (Bryson et al. 2014; Carrieri et al. 2018), we model player salaries as a function of player productivity measures (mean and 


\section{$10 /$ ÖZdemir, Dietl, Rossi ANd Simmons}

standard deviation of on-field performance metrics) and control covariates. Because three teams are relegated from Serie A in each season and we do not observe Serie B earnings, some players in our unbalanced panel data set may appear in one season and disappear the next. In addition, some players may move to other leagues or retire. As salary is an outcome of performance, we cannot regress salary on performance in the same year due to endogeneity concerns. Therefore, salary levels at time $t$ are regressed on performance levels and the associated standard deviation from season $t-1$, where these performance may come from a different club if the player has switched teams.

We control for player age, career games, and national team selection before the beginning of the season. In addition, we use dummies for nonEuropean players, for positions (defender, midfield, forward), and for teams. Similar to numerous researchers who have used the Mincer wage regression, we expect age and number of career games to have a positive but diminishing (i.e., concave) effect on salaries (Bryson et al. 2013). Playing on the national team represents both selection and signaling effect, which will also have a positive effect on salaries. Following Bryson et al. (2014), we expect foreign players to have higher salaries than Italian-born players, reflecting unobserved ability and locational preferences. Moreover, we know from descriptive analyses that attacking players usually earn more than defending players; hence, midfielder and forward dummies are expected to have positive effects on salaries (Frick 2007; Lucifora and Simmons 2003). We also control for teams' ability to pay proxied by previous season's log attendance since we do not observe team revenues over our sample period. Teams with larger attendance are expected to be able to offer larger salaries than teams with smaller attendances.

In equation (1), we are especially interested in the sign and sizes of $\alpha_{2}, \alpha_{4}$, $\alpha_{6}$, and $\alpha_{8}$ to see whether inconsistent performance for different skill sets has different effects on salaries. Our ordinary least squares (OLS) model includes season fixed effects. With seasonal dummies added, we do not deflate salaries by the consumer price index as salary variation may differ from consumer price inflation. Seasonal dummies are more flexible than a linear time trend, especially when the salary variation is non-linear.

Atypically for football salary studies, we also estimate equation (1) using OLS and player fixed effects (FE). The latter controls for unobserved heterogeneity among players in a panel setting. Although this is desirable, it does raise a potential problem that the effect of age is not properly identified due to collinearity with a time trend. However, since we use seasonal dummies instead of a linear time trend, this should not be an issue. 


$$
\begin{aligned}
& \operatorname{LN}\left(\text { SALARY }_{t}\right)=\alpha_{0}+\alpha_{1} \text { CLEARANCES }_{t-1}+\alpha_{2} \text { SD CLEARANCES }_{t-1} \\
& \alpha_{3} \text { AERIAL DUELS WON }_{t-1}+\alpha_{4} \text { SD AERIAL DUELS WON } \text { W }_{t-1} \\
& +\alpha_{5} \text { PASSES }_{t-1}+\alpha_{6} \text { SD PASSES }_{t-1}+\alpha_{7} \text { SHOTS ON TARGET }_{t-1} \\
& +\alpha_{8} \text { SD SHOTS ON TARGET } T_{t-1}+\alpha_{9} A G E_{t}+\alpha_{10} A G E_{t}^{2} \\
& +\alpha_{11} \text { CAREER GAMES }_{t}+\alpha_{12} \text { NATIONALTEAM }_{t-1}+\alpha_{12} \text { NONEU } \\
& +\alpha_{13} L N\left(\text { ATTENDANCE } E_{t-1}\right)+\text { Position }+ \text { Team }+ \text { Season }+ \text { error }
\end{aligned}
$$

The estimation strategy was as follows. To begin, we included means and standard deviations of all 14 skill measures from the list above with the exception, as noted, of goals and assists. We kept the same set of control variables in all estimations. If a particular metric had insignificant coefficients ( $p$ value $>0.1$ with standard errors clustered by player) on both mean and standard deviation, that metric was deleted from the model. Stata's stepwise routine guided the measures to be deleted. This general-to-specific procedure resulted in removal of seven performance measures: key passes, dribbles, tackles, blocked shots, accurate crosses, through balls, and interceptions. We were left with clearances, aerial duels won, passes, and shots on target as skill measures for which either the mean or standard deviation had a significant coefficient at the $10 \%$ level or better. Table 1 gives an overview of dependent and independent variables, while Table 2 shows summary statistics.

\section{Regression Results}

Table 3 presents the regression results for OLS and player FE regressions using a stepwise method to exclude insignificant variables. The control covariates perform as expected and this in itself gives confidence in the results. Age has a positive coefficient, while age squared has a negative coefficient, as is standard in Mincer-type salary models. Here, the turning points for age are 28 for OLS estimation and 25 for the player FE estimation. Increased playing experience through more career games results in higher pay. Playing more games in the most recent season is also associated with higher pay. Coaches tend to use their best players for more games, and the best players will tend to be paid more than inferior players. Players who are born outside the European Union earn higher salaries, as do players who have played recently for their national teams. Players on teams that have larger attendances in their stadiums have higher pay than those on teams with smaller attendances. As noted, we consider attendance to be a proxy for a team's ability to pay its players. 


\section{2 / ÖZdemir, Dietl, Rossi AND SimMONS}

\section{TABLE 1}

List of Dependent and Independent Variables and Their Descriptions

\begin{tabular}{|c|c|}
\hline Variable & Description \\
\hline $\mathrm{LN}\left(\mathrm{SALARY}_{t}\right)$ & Natural logarithm of salary in season $t$ \\
\hline Clearances $_{t-1}$ & Average clearances of the ball from threat on the goal in season $t-1$ \\
\hline $\mathrm{SD}_{\text {Clearances }}{ }_{t-1}$ & Std.dev clearances of the ball from threat on the goal in season $t-1$ \\
\hline Aerial duels won t-1 $_{1}$ & Winning a header in a direct contest with an opponent in season $t-1$ \\
\hline SD Aerials duels won ${ }_{t-1}$ & Std.dev. of winning a header in a direct contest with an opponent in season $t-1$ \\
\hline Passes $_{t-1}$ & Average passes from a player to a teammate season $t-1$ \\
\hline SD Passes $_{t-1}$ & Std.dev of passes from a player to a teammate season $t-1$ \\
\hline Shots on target $t_{t-1}$ & Average shots on target (e.g., goal) per minute in season $t-1$ \\
\hline SD Shots on target $t_{t-1}$ & Std.dev. of shots on target (e.g., goal) per minute in season $t-1$ \\
\hline $\mathrm{AGE}_{t}$ & Age of player in season $t$ \\
\hline $\mathrm{AGE}_{t}^{2}$ & Age squared of player in season $t$ \\
\hline CAREERGAMES $_{t}$ & Cumulative number of career games in the Serie A in season $t$ \\
\hline NATIONALTEAM $_{t-1}$ & Dummy $=1$ if appeared in the national team squad in season $t-1$ \\
\hline $\mathrm{DEF}_{t}$ & Dummy $=1$ if player is a defender \\
\hline $\mathrm{MID}_{t}$ & Dummy $=1$ if player is a midfielder \\
\hline $\mathrm{FORW}_{t}$ & Dummy $=1$ if player is a forward \\
\hline NONEU & Dummy $=1$ if player is a non-European player \\
\hline LN(ATTENDANCE $\left.{ }_{t-1}\right)$ & Natural logarithm of average stadium attendance of team in season $t-1$ \\
\hline Team dummies & Dummy variable for team \\
\hline Season dummies & Dummy variable for season \\
\hline
\end{tabular}

TABLE 2

Descriptive Statistics of Dependent and Independent Variables

\begin{tabular}{|c|c|c|c|c|c|}
\hline Variable & Obs. & Mean & $S D$ & Min & Max \\
\hline $\mathrm{LN}\left(\mathrm{SALARY}_{t}\right)$ & 2049 & 7.308 & 0.808 & 4.094 & 9.616 \\
\hline Clearances $_{t-1}$ & 2049 & 0.027 & 0.026 & 0 & 0.119 \\
\hline SD Clearances $_{t-1}$ & 2049 & 0.02 & 0.012 & 0 & 0.083 \\
\hline Aerial duels won ${ }_{t-1}$ & 2049 & 0.014 & 0.01 & 0 & 0.089 \\
\hline SD Aerials won w $_{t-1}$ & 2049 & 0.015 & 0.008 & 0 & 0.076 \\
\hline Passes $_{t-1}$ & 2049 & 0.424 & 0.141 & 0 & 1.193 \\
\hline SD Passes $_{t-1}$ & 2049 & 0.135 & 0.05 & 0 & 0.558 \\
\hline Shots on target $t_{t-1}$ & 2049 & 0.005 & 0.005 & 0 & 0.032 \\
\hline SD Shots on target $t_{t-1}$ & 2049 & 0.008 & 0.006 & 0 & 0.052 \\
\hline $\mathrm{AGE}_{t}$ & 2049 & 28.128 & 4.147 & 17 & 40.8 \\
\hline $\mathrm{AGE}_{t}^{2}$ & 2049 & 808.372 & 236.167 & 289 & 1664.64 \\
\hline CAREERGAMES $_{t}$ & 2049 & 138.226 & 100.027 & 5 & 619 \\
\hline NATIONALTEAM $_{t}$ & 2049 & 0.54 & 0.499 & 0 & 1 \\
\hline DEFENDER $_{t}$ & 2049 & 0.368 & 0.482 & 0 & 1 \\
\hline MIDFIELDER $_{t}$ & 2049 & 0.429 & 0.495 & 0 & 1 \\
\hline FORWARD $_{\mathrm{t}}$ & 2049 & 0.203 & 0.402 & 0 & 1 \\
\hline NONEU & 2049 & 0.424 & 0.494 & 0 & 1 \\
\hline LN(ATTENDANCE $\left.{ }_{t-1}\right)$ & 2049 & 10.028 & 0.312 & 8.948 & 10.931 \\
\hline
\end{tabular}


TABLE 3

Estimation Results For OLS AND FE Regressions

\begin{tabular}{|c|c|c|}
\hline Dependent variable: $\operatorname{LN}\left(\mathrm{SALARY}_{t}\right)$ & $\begin{array}{l}\text { OLS } \\
(1)\end{array}$ & $\begin{array}{l}\mathrm{FE} \\
\text { (2) }\end{array}$ \\
\hline Clearances $_{t-1}$ & $\begin{array}{l}5.597^{* * *} \\
(1.225)\end{array}$ & $\begin{array}{l}1.408 \\
(1.158)\end{array}$ \\
\hline SD Clearances $_{t-1}$ & $\begin{array}{l}-6.703^{* * *} \\
(2.100)\end{array}$ & $\begin{array}{l}-3.487^{* *} \\
(1.706)\end{array}$ \\
\hline Aerial duels won ${ }_{t-1}$ & $\begin{array}{l}11.213^{* * *} \\
(2.466)\end{array}$ & $\begin{array}{l}2.622 \\
(2.077)\end{array}$ \\
\hline SD Aerials duels won w-1 $_{t}$ & $\begin{array}{l}-16.804^{* * *} \\
(2.895)\end{array}$ & $\begin{array}{l}-6.501^{* * *} \\
(2.434)\end{array}$ \\
\hline Passes $_{t-1}$ & $\begin{array}{l}0.971 * * * \\
(0.155)\end{array}$ & $\begin{array}{l}0.358^{* *} \\
(0.159)\end{array}$ \\
\hline SD Passes $_{t-1}$ & $\begin{array}{l}-0.386 \\
(0.397)\end{array}$ & $\begin{array}{l}-0.111 \\
(0.352)\end{array}$ \\
\hline Shots on target ${ }_{t-1}$ & $\begin{array}{l}53.985^{* * *} \\
(6.809)\end{array}$ & $\begin{array}{l}22.516^{* * * *} \\
(6.382)\end{array}$ \\
\hline SD Shots on target $t_{t-1}$ & $\begin{array}{l}-22.896^{\text {*** }} \\
(4.611)\end{array}$ & $\begin{array}{l}-7.800^{* *} \\
(3.537)\end{array}$ \\
\hline $\mathrm{AGE}_{t}$ & $\begin{array}{l}0.397 * * * \\
(0.046)\end{array}$ & $\begin{array}{l}0.547^{* * *} \\
(0.078)\end{array}$ \\
\hline $\mathrm{AGE}_{t}^{2}$ & $\begin{array}{l}-0.007 * * * \\
(0.001)\end{array}$ & $\begin{array}{l}-0.011^{* * *} \\
(0.001)\end{array}$ \\
\hline CAREERGAMES $_{t}$ & $\begin{array}{l}0.001^{* * *} \\
(0.000)\end{array}$ & $\begin{array}{l}0.006^{* * *} \\
(0.001)\end{array}$ \\
\hline NATIONALTEAM $_{t}$ & $\begin{array}{l}0.143 * * * \\
(0.032)\end{array}$ & $\begin{array}{l}0.096^{* * *} \\
(0.032)\end{array}$ \\
\hline MIDFIELDER $_{t}$ & $\begin{array}{l}0.113^{* *} \\
(0.046)\end{array}$ & \\
\hline FORWARD $_{t}$ & $\begin{array}{l}0.353 * * * \\
(0.073)\end{array}$ & \\
\hline NONEU & $\begin{array}{l}0.093 * * * \\
(0.034)\end{array}$ & \\
\hline LN(ATTENDANCE $\left.{ }_{t-1}\right)$ & $\begin{array}{l}0.322 * * * \\
(0.115)\end{array}$ & $\begin{array}{l}0.033 \\
(0.093)\end{array}$ \\
\hline Constant & $\begin{array}{l}-2.489^{* *} \\
(1.267)\end{array}$ & $\begin{array}{l}-0.093 \\
(1.768)\end{array}$ \\
\hline $\begin{array}{l}\text { Observations } \\
\text { Within } R^{2}\end{array}$ & 2049 & 2049 \\
\hline Overall $R^{2}$ & 0.675 & 0.274 \\
\hline Season Dummies & YES & YES \\
\hline Team Dummies & YES & YES \\
\hline Number of players & & 725 \\
\hline
\end{tabular}

Robust standard errors in parentheses ${ }^{* * *} p<0.01,{ }^{* *} p<0.05,{ }^{*} p<0.1$.

Finally, from the OLS estimates, forwards earn a pay premium relative to midfield and defensive players but we do not find a wage premium for midfield players. 


\section{4 / ÖZdemir, Dietl, Rossi ANd Simmons}

Of all the performance metrics, mean performance of clearances per minute, aerials won per minute, passes per minute, and shots on target per minute each have positive and significant effects on salaries in the OLS regressions (model 1). This is expected, as players who are more active (e.g., passes, shots on target) usually take on more responsibility and perform better.

The standard deviations of the performance measures all have zero or negative impacts on salary. We find no instance where the standard deviation of a performance measure has a positive effect on salary. Hence, these data refute the conjecture of an upside potential of risky workers for footballers in Italy's Serie A. We do, however, find significant negative impacts on salaries for standard deviations of clearances per minute, aerial duels won per minute, and shots on target per minute. The standard deviation of passes per minute has no effect on salaries. For this measure, the mean contains full and sufficient information for salary evaluation of players.

The performance metrics are divided by minutes played; as such, a 1 unit increase in a given metric is an extraordinary increase in performance over an entire season. We therefore interpret the results as elasticities (see Table 4). For example, a proportional increase in mean shots on target per minute of $1 \%$ would lead to an increase in salaries by $3.4 \%$. Increasing the standard deviation in shots on target per minute by $1 \%$ would lead to a decrease in salaries by $2.3 \%$.

TABLE 4

ELASTICITIES FOR OLS AND FE REgRESSIONS

\begin{tabular}{|c|c|c|}
\hline Dependent variable: $\operatorname{LN}\left(\mathrm{SALARY}_{t}\right)$ & $\begin{array}{l}\text { OLS } \\
\text { (1) }\end{array}$ & $\begin{array}{l}\mathrm{FE} \\
(2)\end{array}$ \\
\hline Clearances $_{t-1}$ & $\begin{array}{l}0.021^{* * *} \\
(0.005)\end{array}$ & $\begin{array}{l}0.005 \\
(0.004)\end{array}$ \\
\hline SD Clearances $_{t-1}$ & $\begin{array}{l}-0.019^{* * *} \\
(0.006)\end{array}$ & $\begin{array}{l}-0.010^{* *} \\
(0.005)\end{array}$ \\
\hline Aerial duels won ${ }_{t-1}$ & $\begin{array}{l}0.021^{* * *} \\
(0.005)\end{array}$ & $\begin{array}{l}0.005 \\
(0.004)\end{array}$ \\
\hline SD Aerials duels won ${ }_{t-1}$ & $\begin{array}{l}-0.034^{* * *} \\
(0.006)\end{array}$ & $\begin{array}{l}-0.013^{* * *} \\
(0.005)\end{array}$ \\
\hline Passes $_{t-1}$ & $\begin{array}{l}0.056^{* * *} \\
(0.009)\end{array}$ & $\begin{array}{l}0.021^{* *} \\
(0.009)\end{array}$ \\
\hline SD Passes $_{t-1}$ & $\begin{array}{l}-0.007 \\
(0.007)\end{array}$ & $\begin{array}{l}-0.002 \\
(0.007)\end{array}$ \\
\hline Shots on target $t_{-1}$ & $\begin{array}{l}0.034^{* * *} \\
(0.004)\end{array}$ & $\begin{array}{l}0.014 * * * \\
(0.004)\end{array}$ \\
\hline SD Shots on target $t_{t-1}$ & $\begin{array}{l}-0.023^{* * *} \\
(0.005)\end{array}$ & $\begin{array}{l}-0.008^{* *} \\
(0.004)\end{array}$ \\
\hline
\end{tabular}

Standard errors in parentheses ${ }^{* * *} p<0.01,{ }^{* *} p<0.05,{ }^{*} p<0.1$. 
TABLE 5

Estimation RESULTS FOR QUANTILE Regressions

\begin{tabular}{|c|c|c|c|c|c|}
\hline 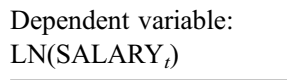 & $\begin{array}{l}\text { (1) } \\
\text { 10th pctile }\end{array}$ & $\begin{array}{l}(2) \\
25 \text { th pctile }\end{array}$ & $\begin{array}{l}(3) \\
\text { Median }\end{array}$ & $\begin{array}{l}\text { (4) } \\
\text { 75th pctile }\end{array}$ & $\begin{array}{l}\text { (5) } \\
\text { 90th pctile }\end{array}$ \\
\hline Clearances $_{t-1}$ & $\begin{array}{l}2.733 \\
(1.757)\end{array}$ & $\begin{array}{l}5.326^{* * *} \\
(1.418)\end{array}$ & $\begin{array}{l}5.437^{* * *} \\
(1.210)\end{array}$ & $\begin{array}{l}6.015^{* * *} \\
(1.364)\end{array}$ & $\begin{array}{l}7.052^{* * *} \\
(2.217)\end{array}$ \\
\hline SD Clearances $_{t-1}$ & $\begin{array}{l}-4.530 \\
(3.020)\end{array}$ & $\begin{array}{l}-6.761^{* * *} \\
(2.421)\end{array}$ & $\begin{array}{l}-8.277^{* * *} \\
(2.246)\end{array}$ & $\begin{array}{l}-8.860^{* * *} \\
(2.328)\end{array}$ & $\begin{array}{l}-6.603^{*} \\
(3.766)\end{array}$ \\
\hline Aerials duels won w $_{t-1}$ & $\begin{array}{l}10.288^{* * *} \\
(3.908)\end{array}$ & $\begin{array}{l}11.337^{* * * *} \\
(2.900)\end{array}$ & $\begin{array}{l}11.735^{* * *} \\
(2.418)\end{array}$ & $\begin{array}{l}11.214^{* * *} \\
(2.613)\end{array}$ & $\begin{array}{l}8.553^{*} \\
(4.735)\end{array}$ \\
\hline SD Aerial duels won w $_{t-1}$ & $\begin{array}{l}-16.129 * * * \\
(4.692)\end{array}$ & $\begin{array}{l}-15.189^{* * * *} \\
(3.399)\end{array}$ & $\begin{array}{l}-16.842^{* * *} \\
(3.203)\end{array}$ & $\begin{array}{l}-17.403^{* * *} \\
(3.376)\end{array}$ & $\begin{array}{l}-15.780^{* * *} \\
(5.407)\end{array}$ \\
\hline Passes $_{t-1}$ & $\begin{array}{l}0.960 * * * \\
(0.230)\end{array}$ & $\begin{array}{l}1.115^{* * *} \\
(0.157)\end{array}$ & $\begin{array}{l}0.945^{* * *} \\
(0.137)\end{array}$ & $\begin{array}{l}0.895^{* * *} \\
(0.177)\end{array}$ & $\begin{array}{l}1.156^{* * *} \\
(0.241)\end{array}$ \\
\hline SD Passes $_{t-1}$ & $\begin{array}{l}-0.323 \\
(0.584)\end{array}$ & $\begin{array}{l}-0.801^{*} \\
(0.450)\end{array}$ & $\begin{array}{l}-0.494 \\
(0.383)\end{array}$ & $\begin{array}{l}-0.250 \\
(0.474)\end{array}$ & $\begin{array}{l}-0.644 \\
(0.582)\end{array}$ \\
\hline Shots on target $t_{t-1}$ & $\begin{array}{l}38.646^{* * *} \\
(10.634)\end{array}$ & $\begin{array}{l}49.772 * * * \\
(8.362)\end{array}$ & $\begin{array}{l}63.974^{* * * *} \\
(8.409)\end{array}$ & $\begin{array}{l}64.263^{* * * *} \\
(7.522)\end{array}$ & $\begin{array}{l}69.114^{* * *} \\
(11.738)\end{array}$ \\
\hline SD Shots on target $t_{t-1}$ & $\begin{array}{l}-11.113 \\
(7.693)\end{array}$ & $\begin{array}{l}-19.269 * * * \\
(5.717)\end{array}$ & $\begin{array}{l}-28.506^{* * *} \\
(5.951)\end{array}$ & $\begin{array}{l}-25.831^{* * *} \\
(5.512)\end{array}$ & $\begin{array}{l}-26.486^{* * *} \\
(7.802)\end{array}$ \\
\hline Observations & 2049 & 2049 & 2049 & 2049 & 2049 \\
\hline Pseudo $R^{2}$ & 0.377 & 0.432 & 0.474 & 0.493 & 0.483 \\
\hline Controls & YES & YES & YES & YES & YES \\
\hline Season Dummies & YES & YES & YES & YES & YES \\
\hline Team Dummies & YES & YES & YES & YES & YES \\
\hline
\end{tabular}

Standard errors in parentheses ${ }^{* * *} p<0.01,{ }^{* *} p<0.05,{ }^{*} p<0.1$.

In the player FE regressions (Table 3, model 2), we show that the standard deviation of clearances per minute, aerial duels won per minute, and shots on target per minute still decrease salaries significantly. Again, we find no support for conjecture of option value or upside potential of risky workers emanating from performance inconsistency. For example, a 1\% increase in standard deviation of shots on target per minute leads to a decrease of $0.8 \%$ in salaries.

Both models show that performance inconsistency is penalized, for both offensive and defensive actions. Passes, clearances, and aerial duels won are all key skills performed by all players independent of their assigned role on the field. An attacking player can win an aerial duel as much as a defending player. However, shots on target is a more skilled and specialized task at which good attacking players will excel and the very best players will perform consistently well.

In the quantile regressions (Table 5), we test the same performance metrics for robustness, using a bootstrapped method with 1000 repetitions (elasticities are shown in Table 6). The key results of OLS and player FE regressions persist. The salary return for mean passes and mean shots on target increases as 
16 / ÖZdEMIR, DietL, Rossi AND SimMONS

TABLE 6

Elasticities for Quantile Regressions

\begin{tabular}{|c|c|c|c|c|c|}
\hline 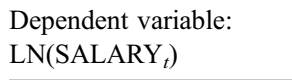 & $\begin{array}{l}\text { (1) } \\
\text { 10th pctile }\end{array}$ & $\begin{array}{l}\text { (2) } \\
\text { 25th pctile }\end{array}$ & $\begin{array}{l}\text { (3) } \\
\text { Median }\end{array}$ & $\begin{array}{l}\text { (4) } \\
\text { 75th pctile }\end{array}$ & $\begin{array}{l}(5) \\
90 \text { th pctile }\end{array}$ \\
\hline Clearances $_{t-1}$ & $\begin{array}{l}0.011 \\
(0.007)\end{array}$ & $\begin{array}{l}0.021^{* * *} \\
(0.006)\end{array}$ & $\begin{array}{l}0.021^{* * *} \\
(0.005)\end{array}$ & $\begin{array}{l}0.022^{* * *} \\
(0.005)\end{array}$ & $\begin{array}{l}0.025^{* * *} \\
(0.008)\end{array}$ \\
\hline SD Clearances $_{t-1}$ & $\begin{array}{l}-0.014 \\
(0.009)\end{array}$ & $\begin{array}{l}-0.020^{* * *} \\
(0.007)\end{array}$ & $\begin{array}{l}-0.024 * * * \\
(0.006)\end{array}$ & $\begin{array}{l}-0.024 * * * \\
(0.006)\end{array}$ & $\begin{array}{l}-0.017^{*} \\
(0.010)\end{array}$ \\
\hline Aerials duels won w $_{t-1}$ & $\begin{array}{l}0.021^{* * *} \\
(0.008)\end{array}$ & $\begin{array}{l}0.022^{* * *} \\
(0.006)\end{array}$ & $\begin{array}{l}0.022^{* * * *} \\
(0.005)\end{array}$ & $\begin{array}{l}0.021^{* * *} \\
(0.005)\end{array}$ & $\begin{array}{l}0.015^{*} \\
(0.008)\end{array}$ \\
\hline SD Aerial duels won ${ }_{t-1}$ & $\begin{array}{l}-0.035^{\text {*** }} \\
(0.010)\end{array}$ & $\begin{array}{l}-0.032^{* * *} \\
(0.007)\end{array}$ & $\begin{array}{l}-0.034^{* * *} \\
(0.007)\end{array}$ & $\begin{array}{l}-0.034^{* * *} \\
(0.007)\end{array}$ & $\begin{array}{l}-0.030^{* * *} \\
(0.010)\end{array}$ \\
\hline Passes $_{t-1}$ & $\begin{array}{l}0.060^{* * * *} \\
(0.014)\end{array}$ & $\begin{array}{l}0.067^{* * * *} \\
(0.009)\end{array}$ & $\begin{array}{l}0.055^{* * * *} \\
(0.008)\end{array}$ & $\begin{array}{l}0.050^{* * * *} \\
(0.010)\end{array}$ & $\begin{array}{l}0.062^{* * * *} \\
(0.013)\end{array}$ \\
\hline SD Passes $_{t-1}$ & $\begin{array}{l}-0.006 \\
(0.012)\end{array}$ & $\begin{array}{l}-0.015^{*} \\
(0.009)\end{array}$ & $\begin{array}{l}-0.009 \\
(0.007)\end{array}$ & $\begin{array}{l}-0.004 \\
(0.008)\end{array}$ & $\begin{array}{l}-0.011 \\
(0.010)\end{array}$ \\
\hline Shots on target $t_{t-1}$ & $\begin{array}{l}0.027^{* * *} \\
(0.007)\end{array}$ & $\begin{array}{l}0.033^{* * * *} \\
(0.005)\end{array}$ & $\begin{array}{l}0.041^{* * * *} \\
(0.005)\end{array}$ & $\begin{array}{l}0.039^{* * * *} \\
(0.005)\end{array}$ & $\begin{array}{l}0.040^{* * *} \\
(0.007)\end{array}$ \\
\hline SD Shots on target $t_{t-1}$ & $\begin{array}{l}-0.012 \\
(0.009)\end{array}$ & $\begin{array}{l}-0.021^{\text {*** }} \\
(0.006)\end{array}$ & $\begin{array}{l}-0.029^{* * *} \\
(0.006)\end{array}$ & $\begin{array}{l}-0.025^{* * *} \\
(0.005)\end{array}$ & $\begin{array}{l}-0.025^{* * *} \\
(0.007)\end{array}$ \\
\hline
\end{tabular}

Standard errors in parentheses $* * * p<0.01,{ }^{*} * p<0.05, * p<0.1$.

we move up the salary distribution. Greater inconsistency in clearances per minute leads to significantly lower salaries at all percentiles except the 10th. The standard deviation of aerial duels won per minute and shots on target per minute has a significant negative coefficient at all percentiles of the salary distribution. The absolute magnitude of the coefficient of standard deviation of shots on target per minute rises with salary, although the standard deviation of shots on target per minute is not significant at the 10th percentile. Overall, inconsistency in shots on target per minute is more harshly penalized at the higher end of the salary distribution. This is consistent with the industry view that star football players need to perform at a consistently high level in order to earn lucrative contracts and sustain their very large salaries.

These results are in line with those of Deutscher et al. (2017). In the NBA, greater inconsistency in scoring and non-scoring skills led to lower salaries. In contrast to Deutscher and Büschemann (2016), we use detailed performance metrics rather than composite ratings (e.g., from journalists) and found that inconsistency leads to salary penalties instead of premia.

\section{Discussion and Conclusion}

Are workers rewarded for inconsistent performance? Using eight seasons' data (2009-10 to 2016-17) from Italian professional football $(78,302$ player- 
match observations; 2049 player-team observations), we find no salary premia for inconsistency. On the contrary, inconsistency is penalized for three dimensions of performance: clearances, aerial duels won, and shots on target. These findings reinforce previous results from NBA data that show negative effects of performance inconsistency. In football as in basketball, the highest salaries go to players who consistently perform at high levels. Unlike some previous studies (Deutscher and Büschemann 2016), we take the view that single indicators for overall performance are not sufficient to test this relationship, notably because single indicators cannot capture the complexity of different skill sets needed for different roles. Instead of overall performance grades, we use on-field performance metrics. This facilitates a richer evaluation of effects of player performance where returns to specific skills can be determined. Our results suggest that a simple focus on performance variation in one metric (either subjective or through assessors' algorithm) is inadequate for consideration of salary determination and a multi-task approach is worthwhile.

Although we exploit a rich data set for our paper, there are some technical limitations that should be noted. Measuring individual performance in team sports is not always conclusive. For an attacking player, one can count the number of dribbles, shots on target, assists, and goals. It is much more difficult, however, to measure the performance of a defensive or midfield player. Good defending is usually a team effort that requires considerable coordination among team members. For example, midfielders have both attacking and defensive responsibilities: They are called upon to "turn the play around" by regaining possession of the ball for their team. The skill and effort demonstrated in that task are hard to capture empirically.

Moreover, positional play in defense is an important skill that cannot be as easily measured as blocked shots or tackles. Indeed, tackles themselves might be the outcome of bad positional play. Thus, depending on the situation, a tackle can be the result of good defense or bad. This is a common problem in fluid sports: We can observe the game and measure what is happening on the field, but we cannot easily measure what does not happen, for example, a lost attacking chance because the defending team had extraordinary positional play or the offensive team made poor decisions.

Lately, analysts and researchers have introduced new performance metrics, such as expected goals (Brechot and Flepp 2020; Flepp and Franck 2021) or plus-minus ratings (Kharrat et al. 2020), the latter adapted from ice hockey and basketball. Expected goals is a measure that calculates the probability of scoring a goal, given the location of the shot taken, the body part the shot has been taken with (foot or head), whether the shot has been taken in open play or in a free kick, the existence of opposing players between the shooter and the goal, and the likes. The measure has gained popularity recently and has 


\section{8 / ÖZdemir, Dietl, Rossi AND Simmons}

been shown to more closely assess team and individual player performance than basic league standings or points won per game. On the other hand, plusminus ratings assess a player's contribution to team success in that the metric compares what happens if a player is on versus off the field.

As sports analytics develops further, we expect better metrics for all players to emerge with explicit consideration of the context for player actions. Such improved measures will greatly facilitate analysis of salary determination in team sports.

\section{REFERENCES}

Adler, Moshe. 1985. "Stardom and Talent." American Economic Review 75(1): 208-12.

Ashenfelter, Orley, and Alan B. Krueger. 1994. "Estimates of the Economic Return to Schooling from a New Sample of Twins." American Economic Review 84(5): 1157-73.

Barrett, Alan, and Philip J. O’Connell. 2001. "Does Training Generally Work? The Returns to In-Company Training." Industrial and Labor Relations Review 54(3): 647-62.

Berri, David, Babatunde Buraimo, Giambattista Rossi, and Rob Simmons. 2016. "Pay and Performance in Italian Football.” Birkbeck Sport Business Centre Research Paper Series, October(9).

Bils, Mark, and Peter J. Klenow. 2000. "Does Schooling Cause Growth?" American Economic Review 90 (5): 1160-83.

Bodvarsson, Örn B., and Raymond T. Brastow. 1998. "Do Employers Pay for Consistent Performance? Evidence from the NBA." Economic Inquiry 36(1): 145-60.

Bollinger, Christopher R., and Julie L. Hotchkiss. 2003. "The Upside Potential of Hiring Risky Workers: Evidence from the Baseball Industry." Journal of Labor Economics 21(4): 923-44. https://doi.org/10. $1086 / 377027$.

Brechot, Marc, and Raphael, Flepp. (2020). Dealing with Randomness in Match Outcomes: How to Rethink Performance Evaluation in European Club Football Using Expected Goals. Journal of Sports Economics, 21(4), 335-362. http://doi.org/10.1177/1527002519897962

Bryson, Alex, Bernd Frick, and Robert Simmons. 2013. "The Returns to Scarce Talent: Footedness and Player Remuneration in European Soccer.” Journal of Sports Economics 14(6): 606-28. https://doi. org/10.1177/1527002511435118.

Bryson, Alex, Giambattista Rossi, and Rob Simmons. 2014. "The Migrant Wage Premium in Professional Football: A Superstar Effect?" Kyklos 67(1): 12-28.

Buraimo, Babatunde, Bernd Frick, Michael Hickfang, and Rob Simmons. 2015. "The Economics of LongTerm Contracts in the Footballers' Labour Market." Scottish Journal of Political Economy 62(1): 824. https://doi.org/10.1111/sjpe.12064.

Card, David, and Alan B. Krueger. 1992. "Does School Quality Matter? Returns to Education and the Characteristics of Public Schools in the United States." Journal of Political Economy 100(1): 1-40.

Carrieri, Vincenzo, Francesco Principe, and Michele Raitano. 2018. "What Makes You "Super-Rich"? New Evidence from an Analysis of Football Players' Wages." Oxford Economic Papers 70(4): 950-73. https://doi.org/10.1093/oep/gpy025.

Cattell, Raymond B. 1978. The Scientific Use of Factor Analysis in Behavioral and Life Sciences. Boston, MA: Springer US.

Chapman, Kenneth S., and Lawrence Southwick. 1991. "Testing the Matching Hypothesis: The Case of Major-League Baseball.” American Economic Review 81(5): 1352-60.

Deutscher, Christian, and Arne Büschemann. 2016. "Does Performance Consistency Pay Off Financially for Players? Evidence from the Bundesliga.” Journal of Sports Economics 17(1): 27-43. https://doi.org/ $10.1177 / 1527002514521428$. 


\section{Are Workers Rewarded for Inconsistent Performance?}

Deutscher, Christian, Oliver Gürtler, Joachim Prinz, and Daniel Weimar. 2017. "The Payoff to Consistency in Performance.” Economic Inquiry 55(2): 1091-103. https://doi.org/10.1111/ecin.12415.

Dickinson, David L., and Ronald L. Oaxaca. 2014. "Wages, Employment, and Statistical Discrimination: Evidence from the Laboratory." Economic Inquiry 52(4): 1380-91. https://doi.org/10.1111/ecin.12103

Ernst, Holger, and Jan Vitt. 2000. "The Influence of Corporate Acquisitions on the Behaviour of Key Inventors." R\&D Management 30(2): 105-20.

Flepp, Raphael, and Egon Franck. 2021. "The Performance Effects of Wise and Unwise Managerial Dismissals.” Economic Inquiry 59(1): 186-98. https://doi.org/10.1111/ecin.12924.

Frick, Bernd. 2007. “The Football Players' Labor Market: Empirical Evidence from the Major European Leagues." Scottish Journal of Political Economy 54(3): 422-46. https://doi.org/10.1111/j.1467-9485. 2007.00423.X

Fumarco, Luca, and Giambattista Rossi. 2018. "The Relative Age Effect on Labour Market Outcomes - Evidence from Italian Football.” European Sport Management Quarterly 75(1): 1-16. https://doi.org/10. 1080/16184742.2018.1424225.

Garen, John. 1988. "Empirical Studies of the Job Matching Hypothesis." Research in Labor Economics 9 (1988): 187-224.

Gauriot, Romain, and Lionel Page. 2019. "Fooled by Performance Randomness: Overrewarding Luck." The Review of Economics and Statistics 101(4): 658-666. https://doi.org/10.1162/rest_a_00783.

Groysberg, Boris, Linda-Eling Lee, and Ashish Nanda. 2008. "Can They Take It with Them? The Portability of Star Knowledge Workers' Performance.” Management Science 54(7): 1213-30. https://doi.org/10. 1287/mnsc. 1070.0809 .

Kahn, Lawrence M. 2000. "The Sports Business as a Labor Market Laboratory.” Journal of Economic Perspectives 14(3): 75-94. https://doi.org/10.1257/jep.14.3.75.

Kempa, Karol. 2021. "Task-specific Human Capital and Returns to Specialization: Evidence from Association Football." Oxford Economic Papers, https://doi.org/10.1093/oep/gpab006.

Kharrat, Tarak, Ian G. McHale, and Javier López Peña. 2020. "Plus-Minus Player Ratings for Soccer." European Journal of Operational Research 283(2): 726-36. https://doi.org/10.1016/j.ejor.2019.11.026.

Lazear, Edward P. 1998. "Hiring Risky Workers." In Internal Labour Markets, Incentives and Employment, edited by I. Ohashi and Toshiaki Tachibanaki, pp. 143-58. London: Palgrave Macmillan UK.

Lucifora, Claudio, and Rob Simmons. 2003. "Superstar Effects in Sport." Journal of Sports Economics 4(1): 35-55. https://doi.org/10.1177/1527002502239657.

Malmendier, Ulrike, and Geoffrey Tate. 2009. "Superstar CEOs." The Quarterly Journal of Economics 124 (4): 1593-638. https://doi.org/10.1162/qjec.2009.124.4.1593.

Mincer, Jacob. 1974. Schooling, Experience, and Earnings. Human Behavior and Social Institutions: No. 2. New York, NY: National Bureau of Economic Research.

Mueller, Charles W., and Jae-On Kim. 1978. Factor Analysis: Statistical Methods and Practical Issues. Quantitative Applications in the Social Sciences: No. 07-014. Beverly Hills, CA: Sage.

Müller, Oliver, Alexander Simons, and Markus Weinmann. 2017. "Beyond Crowd Judgments: Data-Driven Estimation of Market Value in Association Football." European Journal of Operational Research 263 (2): 611-24. https://doi.org/10.1016/j.ejor.2017.05.005.

Narin, Francis, and Anthony Breitzman. 1995. "Inventive Productivity." Research Policy 24(4): 507-19. https://doi.org/10.1016/S0048-7333(94)00780-2.

Ravid, S. Abraham. 1999. "Information, Blockbusters, and Stars: A Study of the Film Industry." The Journal of Business 72(4): 463-92.

Rosen, Sherwin. 1981. "The Economics of Superstars.” American Economic Review 71(5): 845-58.

Thrane, Christer. 2019. "Performance and Actual Pay in Norwegian Soccer." Journal of Sports Economics 20(8): 1051-65. https://doi.org/10.1177/1527002519851146. 